\title{
Trabajo social enactado: el rol mediador de normas y decretos legales ${ }^{1}$
}

\author{
Social work enacted: the mediator role of norms and legal edicts
}

\author{
Raúl Hozven Valenzuela ${ }^{a}$ Enrique Baleriola Escudero ${ }^{b}$ \\ aPontificia Universidad Católica de Valparaíso, Chile, $\measuredangle$ raul.hozven.v@hotmail.com \\ [orcid.org/0000-0001-5802-0635] \\ bPontificia Universidad Católica de Valparaíso, Chile, enrique.baleriola@pucv.cl \\ [orcid.org/0000-0003-2899-6316]
}

\section{RESUMEN}

El presente artículo se pregunta respecto a cómo comprender la producción del trabajo social chileno. En consideración a lo anterior, el concepto "enactment" que emerge en la Teoría del Actor-Red (ANT) resulta clarificador para entender la configuración de una realidad social con participación de actantes humanos y no-humanos que convergen en la arquitectura de esta profesión. Como resultado, emerge una red híbrida que teje mediaciones y traducciones donde las leyes y decretos legales juegan un papel clave para esclarecer los puntos principales que constituyen el trabajo social chileno contemporáneo.

PALABRAS CLAVE: enactment, mediación, leyes, Teoría del Actor-Red, trabajo social.

\section{ABSTRACT}

This article asks about how to understand the production of Chilean social work. The concept of enactment that emerges from the Actor-Network Theory (ANT) is key to understand the configuration of a social reality where human and non-humans participate in the constitution of the architecture of this profession. As a result, a hybrid network

1 Este trabajo cuenta con el apoyo del Programa PIA-CONICYT a través del Proyecto CIE 160009, simultáneamente con el Fondo Nacional para el Desarrollo y la Tecnología (Proyecto FONDECYT Iniciación 11190195) y también con el Fondo de Investigación Interna de la Universidad Santo Tomás (UST), mediante el Proyecto Categoría Regular No 22721. Período 2016-2017. 
emerges that weave mediations and translations in which laws and legal edicts play a key role in order to clarify the main points that constitute the contemporary Chilean social work.

KEY WORDS: enactment, mediation, laws, Actor-Network Theory, social work.

\section{INTRODUCCIÓN}

Las profesiones de las ciencias humanas desplegadas en escenarios laborales vinculados con políticas sociales se encuentran sumergidas en un escenario de profundas transformaciones producto de las prescripciones del Nuevo Management Público (NMP) (Sisto \& Fardella, 2014). En el caso concreto del trabajo social, la cajanegrización ${ }^{2}$ presenta tensiones por su instrumentalismo (Arriagada, 2017) estandarizado en indicadores, y la ausencia de un núcleo curricular común (González, 2010). Esto implica una dispersión en el posicionamiento ontológico, epistemológico, teórico y metodológico sobre la profesión del trabajo social (Matus, 2016; Molina, 2016; Vidal, 2016; Vivero, 2016), así como tracciones en su empleabilidad, considerando la cantidad de egresados anuales (Rodríguez \& Vidal, 2013; Aspeé, 2016; Castillo \& Rodríguez, 2016) y también por su giro hacia la instrucción en institutos profesionales.

Por ende, es dable descajanegrizar ${ }^{3}$ y no concluir este proceso como automatizado y dado por hecho, pues este panorama corresponde a un arco posible de observar desde materialidades que imprimen relaciones, mediando, generando efectos y ordenamientos en la realidad (Bruni, 2005). En concreto, para el caso del trabajo social, este escenario se caracteriza especialmente por estrategias asentadas en una densa relación con cuerpos jurídicos enmarcadas en un contexto social y cultural complejo, interrelacionado con fenómenos sociales y el mandato institucional que sanciona y determina (Brezmes, 2009). Así, el panorama actual del trabajo social en Chile se funda bajo un dominio de aspectos materiales que posibilitan una marcada dirección, dejando de lado otras posibles.

En este sentido, el presente artículo gira en torno a la conformación de aquel entramado legal-material que divide y fragmenta al trabajo social en diferentes vertientes, conformando un panorama actual confuso y fraccionado. Para ello, analizaremos la Ley $\mathrm{N}^{0}$ 20.054, cuerpo jurídico que sanciona un trabajo social con licenciatura en universidades públicas o privadas, otro trabajo social sin licenciatura en institutos profesionales (IP), y programas de licenciatura tardía que se destinan a profesionales que diferidamente acceden al grado académico, en universidades que lo implementen. Esta ley, que conforma la actual formación tanto profesional

2 Cajanegrizar se basa en la metáfora de una caja negra, utilizada para dar cuenta de un proceso social, trabajo técnico o sistema que se invisibiliza producto de su éxito, omitiendo su complejidad interior. Se utiliza en el marco de los estudios de ciencia, tecnología y sociedad, emergiendo con propiedad en el contexto de la obra de Bruno Latour (2001).

3 Descajanegrizar se vincula con el proceso contrario a la cajanegrización, correspondiendo a la apertura de esa caja negra con el fin de complejizar describiendo densamente los actores, redes y asociaciones que componen un proceso social particular. 
como de grado, implica cambios en las tradiciones e identidad laboral, las cuales, además, devienen aún más complejizadas por el libre mercado y en general por el NMP.

Por ello, este problema es relevante abordarlo por tres motivos principales: a) dar cuenta de las estrategias que un modelo económico particular inscribe sobre las profesiones para homogeneizarlas en base a supuestos ideológicos; b) entender las complejidades para acceder a un puesto laboral, en virtud a materialidades que actúan sobre esta esfera y que tienen como objeto prescribir y vigilar; y c) comprender cómo las desregulaciones en el mercado de trabajo precarizan, desprofesionalizan y tensionan el estatus del trabajo social en los puestos laborales relacionados con las ciencias humanas (Iturrieta, 2012), en donde cabe preguntarse por la consistencia identitaria en escenarios laborales complejos en un tejido social y laboral rizomático.

Debido a estos motivos, se ha considerado relevante emplear el marco conceptual de la Teoría del Actor-Red (ANT, por sus siglas en inglés), para describir la constitución o el enactment ${ }^{4}$ actual de esta profesión, apareciendo con propiedad los actores no-humanos legales y jurídicos tales como los Decretos con Fuerza de Ley (DFL) No 1 y No5 de la década de los ochenta; otras materialidades en los noventa como la Ley No 18.962 Orgánica Constitucional de Enseñanza (LOCE); en este siglo, la Ley No20.054 y No 20.370 y Dictámenes como el No 43.184 y No 39.296 .

Con estas consideraciones, el presente artículo se estructura en base a las siguientes secciones, en la primera se comparte una aproximación teórica y terminológica con raíz en la ANT que nos permitirá comprender el enactment del trabajo social actual en Chile. En el segundo apartado se realiza el análisis de diferentes materialidades jurídicas que han resultado clave en ese ejercicio de enact. Este análisis está compuesto por tres ejes: a) el primero, denominado el origen de la trifurcación, b) la liquidación de una esperanza y c) coherencias paradójicas. Finalmente, daremos a conocer las conclusiones que presentan diferentes líneas de fuga para ser constituidas como alternativas de cambio a la actual constitución del trabajo social chileno.

\section{TEORÍA DEL ACTOR-RED: ENTRE MEDIACIONES Y ENACTMENT}

La Teoría del Actor-Red (ANT, por sus siglas en inglés), surgida en Francia en la década de los 80, como nos recuerda Mike Michael (2017) parafraseando a Bruno Latour, uno de sus fundadores, en realidad no se trata tanto de una teoría ya que su nombre contiene cuatro errores: teoría, actor, red y el guión que une las palabras. En este sentido, un nombre mucho más preciso es el de ontología del actante-rizoma (Latour, 2005), puesto que se trata más bien de una caja de herramientas, un set de conceptos en los que apoyarse metodológica

4 En inglés, enactment significa formar en el sentido de dar forma, o constituir. Dentro del vocabulario de la Teoría del Actor-Red, algunos autores lo han traducido por "constituir" o "promulgar", pero consideramos que ninguna de las dos acepciones recoge acertadamente el matiz que estamos desarrollando en este artículo. En el siguiente apartado, referido a la Teoría del Actor-Red, explicamos más exhaustivamente esta acepción. Es por esto que mantendremos el término en inglés a lo largo de todo el artículo. 
y teóricamente para describir y analizar la forma en que ciertas realidades (formadas por elementos humanos y no-humanos) son construidas y mantenidas en el tiempo.

$\mathrm{Y}$ es precisamente este proceso de construir, promulgar o constituir una realidad formada por humanos y no-humanos y su capacidad de mantenerse en el tiempo lo que recientemente se ha debatido más en el ámbito de los estudios sociales de la ciencia y la tecnología, en concreto en la Teoría del Actor-Red. Si nos tuviésemos que quedar tan solo con dos elementos para definir la esencia de la ANT, estos serían los de enactment y mediación.

Respecto al primer término, enactment, no hay una traducción al español exacta, se puede establecer que corresponde a una "descripción de prácticas en el aquí y el ahora que producen efectos efímeros, efectos esencialmente coextensivos con las prácticas que los han creado" (Woolgar \& Lezaun, 2015, p. 463)

Por otra parte, el concepto de mediación ha sido descrito y analizado de diversas formas, pero lo que une a todas ellas es la capacidad de unir diversos elementos y dar cuenta de cómo ocurre esta unión, retomando los trabajos originales latourianos en un laboratorio, cuando un descubrimiento científico debía asociarse y enrolar a otros actores (artículos, congresos, dinero, científicos, ordenadores), para no perderse en un cajón olvidado. Específicamente, esa capacidad de unir a la que alude la mediación vamos a desarrollar mediante tres acepciones.

En primer lugar, mediación para Latour corresponde a una serie de metas, pasos e intenciones que un agente puede describir en un relato ${ }^{6}$ (Latour, 1994, p. 32), esto es, lo que tradicionalmente se ha conocido en la ANT como traducción significa desplazamiento, deriva, invención; la creación de un lazo que no existía y que modifica elementos. En un segundo momento, mediación significa componer, entendido como el proceso de agencia no de manera individual por parte de una persona o un objeto, sino en co-acción por una red de humanos y no-humanos. La mejor ilustración de esto es la conocida frase de Latour que reza: "los B-52 no vuelan, vuelan las Fuerzas Armadas de los Estados Unidos", refiriéndose a que para que un B-52 vuele es necesario un piloto, soldados, un discurso sobre la guerra, financiamiento, un gobierno que comande al escuadrón de B-52, etcétera (Latour, 1994, p. 32).

Finalmente encontramos que mediación se refiere a delegación. Mediar, para Latour, significa modificar el contenido de la realidad que es mediada por el mediador. Esto es, cuando un elemento nuevo comienza a mediar en una realidad ya existente (formada por elementos humanos y no-humanos), este nuevo elemento lo que está haciendo es modificar y redefinir esa realidad. Los ejemplos son múltiples, uno sencillo es el del profesor de bellas artes que explica cuadros a sus alumnos en una universidad. Si súbitamente un elemento cambia (por ejemplo, el lugar-universidad por el lugar-museo), la realidad-profesor se redefine y pasaría a ser un guía de museo.

Traducción propia.

Traducción propia. 
Volviendo a la concepción de la ANT como caja de herramientas, es por lo recién explicado que usaremos los conceptos de enactment y mediación con el objetivo de describir cómo es enactada la realidad del trabajo social contemporánea en Chile, por mediación de diferentes leyes y decretos.

Por tanto, el sentido de utilizar la ANT en este análisis jurídico se justifica con la finalidad de evidenciar los entramados presentes en las decisiones y acciones realizadas por una diversidad de actantes que son parte de la solución de un problema colectivo (GrauSolés, Iñiguez-Rueda \& Subirats, 2010) tal como es la actual división en el campo del trabajo social. Así, dado que para la ANT lo social no debe entenderse como la causa, sino como el producto dentro de una problemática social (Michael, 2017), esta teoría resuelve la dificultad de encontrar las tramas de inteligibilidad y los caminos por los que se ha llegado a esta fragmentación del trabajo social, haciendo uso para ello de una multiplicidad de recursos humanos y no-humanos en un escenario en donde hay instituciones que reglamentan y pautan las acciones que el elemento social puede llevar a cabo.

\section{METODOLOGÍA DE INVESTIGACIÓN Y PROCEDIMIENTOS}

El presente trabajo ha sido elaborado siguiendo el marco de una investigación cualitativa (Guba \& Lincoln, 1994; Flick, 2012) desde el ámbito de la Teoría del Actor-Red ya comentado. Consideramos que esta articulación es relevante y útil dado que las metodologías cualitativas son las más apropiadas para describir en detalle el enactment de una realidad particular, así como las asociaciones que tejen y componen a la misma. Dentro de las diferentes miradas y acentos que ofrece el trabajo cualitativo, nos hemos decantado por un estudio de caso como la mejor forma de abordar la problemática acerca del estatus actual del trabajo social en Chile. Los estudios de caso (Yin, 1994) son una metodología que permite trabajar con todo tipo de técnicas de recogida de datos y materiales en torno a los cuales se plantee una misma pregunta de investigación. En concreto, en el presente trabajo el caso al que nos referimos es el mencionado estatus legal del trabajo social chileno contemporáneo. La ventaja de este abordaje es la posibilidad de analizar la problemática en cuestión desde un prisma no demasiado abstracto o macro, ni tampoco tan específico o micro que se pierdan las relaciones con otros cuerpos legales u otros actantes relevantes.

En síntesis, el corpus del estudio lo componen las siguientes normativas y leyes: los Decretos con Fuerza de Ley (DFL) Nº 1 y Nº5, la Ley No 18.962 Orgánica Constitucional de Enseñanza (LOCE), la Ley No20.054, Ley No 20.370 y Dictámenes No 43.184 y No 39.296. En ellas, hemos rastreado las tramas de inteligibilidad que dan sentido y componen la problemática anteriormente planteada. Para su análisis apostamos por la utilización del procedimiento que Geertz (2003) denomina descripción densa, típicamente empleado en estudios de caso como el presente.

La descripción densa se caracteriza por cuatro principios: a) ser un ejercicio microscópico, centrado en lo concreto, la percepción del detalle y el énfasis en las 
interacciones, b) supone un esfuerzo interpretativo por el que se persigue encontrar y ligar esas tramas de inteligibilidad que constituyen el estatus legal del trabajo social chileno contemporáneo, c) se basa en una coproducción donde el investigador no encuentra una verdad objetiva y universal, sino más bien la coproduce: teoría y análisis son indisociables, y d) la importancia de la interacción social, especificando las relaciones entre los distintos actantes (humanos y no-humanos) que enactan la organización específica que éstos toman en la problemática estudiada.

Finalmente, los resultados presentados a continuación suponen un momento de espera, siempre preliminar y nunca final en términos absolutos, sobre las tramas de inteligibilidad encontradas en los materiales anteriormente presentados. Estos resultados los presentamos bajo una descripción saturada que consiste, en palabras de Gálvez (2005, p. 5):

Cuando tenemos ante nosotros/as un juego de relaciones interactuando, auto determinándose y estableciendo de manera inmanente las condiciones de su comprensión no se requiere la diferenciación entre un "cómo" y un "por qué". De hecho, la explicación emerge una vez que la descripción empieza a estar saturada, y cuanto más lo esté, mejor será esta última.

Así este procedimiento nos otorga la ventaja de poder desplegar los puntos y momentos más relevantes en la constitución del actual estatus legal del trabajo social chileno bajo la forma de un relato descriptivo en el que se despliegan y describen todas las relaciones, mediaciones y agenciamientos que lo conforman.

\section{RESULTADOS}

\section{El origen de la trifurcación}

El momento principal que da lugar a los tres rostros o fragmentaciones en el trabajo social tiene lugar con el papel de un actante fundamental en lo que respecta al estatus de la profesión en los últimos años, y que corresponde a la Ley N²0.054 del 27 de septiembre de 2005 , y mediante la cual se recupera el rango universitario perdido (ratificado con la Ley $\mathrm{N}^{\circ}$ 18.962 Orgánica Constitucional de Enseñanza, LOCE). De este modo, con esta materialidad emerge la trifurcación en trabajo social, pues aparece como profesión con licenciatura forjada en universidades privadas y públicas, pero también un trabajo social o servicio social sin licenciatura que brota en los institutos profesionales y, por último, programas específicos de licenciatura tardía para los profesionales que se formaron en institutos y que pueden ser implementados por universidades que las ofrezcan.

Pero esta triple vía que caracteriza al trabajo social contemporáneo comienza mucho antes, con el Decreto con Fuerza de Ley $\mathrm{N}^{\circ} 1$ (DFL N ${ }^{\circ}$ ) del 3 de enero de 1981, del Ministerio de 
Educación Pública, que fija normas sobre las Universidades. En el artículo $\mathrm{N}^{\circ} 1$ se plantea que “(...) la Universidad es una institución de educación superior, de investigación, raciocinio y cultura que, en el cumplimiento de sus funciones, debe atender adecuadamente los intereses y necesidades del país, al más alto nivel de excelencia (...)" (Ministerio de Educación Pública de Chile, 1981a, p. 1).

No obstante, lo complejo para el entonces denominado servicio social, se remite al artículo $\mathrm{N}^{\circ} 12$, por cuanto esta profesión no aparece dentro de los títulos profesionales que requieren haber obtenido el grado de licenciado. Cristaliza entonces la pérdida del rango universitario, por ende, esta profesión no está en el cuadro académico en el que se amerita la investigación, el raciocinio y la cultura, si se observa el artículo $\mathrm{N}^{\circ} 1$ del DFL $\mathrm{N}^{\circ} 1$.

Sin embargo, no solo aquello, pues conforme el Decreto con Fuerza de Ley N ${ }^{\circ} 5$ (DFL N 5 ) del 16 de febrero de 1981, del Ministerio de Educación Pública, en su título I, plantea el origen y funcionamiento de los Institutos Profesionales (IP): "son instituciones de educación superior que, en el cumplimiento de sus funciones, deben atender adecuadamente los intereses y necesidades del país, mediante la formación de profesionales con los conocimientos necesarios para el ejercicio de sus respectivas actividades" (Ministerio de Educación Pública de Chile, 1981b, p. 1).

En su artículo segundo, establece:

Corresponde a estos organismos otorgar toda clase de títulos profesionales con excepción de aquellos respecto de los cuales la ley requiera haber obtenido previamente el grado de Licenciado, en una disciplina determinada. Podrán, además, otorgar títulos técnicos dentro del área o ámbito de las profesiones respecto de las cuales otorguen títulos profesionales (...) (Ministerio de Educación Pública de Chile, 1981b, p. 1).

Este apartado es sugestivo por cuanto condensa la apertura de la educación en este nivel formativo, lo que, además, va graficando la política de libre mercado del gobierno de facto. En este momento comienza también a emerger la formación técnica en complemento a las profesionales que experimentan una transición a lo técnico-procedimental. Progresivamente se irán conformando los IP en nuestro país como táctica política en materia educativa.

En el origen de la trifurcación, cabe destacar lo acaecido el 10 de marzo de 1990 cuando un día antes de la recuperación de la democracia nace la Ley № 18.962, Orgánica Constitucional de Enseñanza (LOCE), materialidad concéntrica del aquel entonces Ministerio de Educación Pública. En el artículo $\mathrm{N}^{\circ} 52$, para el caso del denominado en ese entonces servicio social, éste sigue sin aparecer junto con las profesiones que ameritan contar con Licenciatura. Por ende, mediante esta materialidad jurídica se sigue ratificando la pérdida del rango universitario.

En términos de la ANT, podemos resumir que las producciones de políticas corresponden al enactment de una nueva configuración de la realidad, lo que produce un deslizamiento de determinados aspectos para constituir un nuevo contexto político. De este modo, el origen de la trifurcación es ensamblado a través de los mencionados decretos y leyes, los cuales 
tejen diferentes rutas estratégicas de acción de las que participan diferentes actores (colegio de trabajadores sociales, universidades, políticas), procedimientos, tiempos (dictadura, transición, democracia) e instrumentos (leyes, decretos) en un mismo plano, constituyendo así un cosmos político, una cosmopolítica (Stengers, 2005) que enacta esa triple fragmentación del trabajo social actual. En términos ANT, estas normas devienen como elementos en la mediación del trabajo social chileno contemporáneo.

\section{Liquidación de una esperanza}

Esta triple vía en el trabajo social, abierta por los decretos y normativas, se complejiza cuando emerge un fenómeno interesante que curiosamente da cuenta de un espacio de resistencia a la configuración del trabajo social anteriormente comentada desde inicios de los ochenta. La esperanza que da nombre a este apartado se refiere a la ilusión por constituir un nuevo estatuto del trabajo social en el que los institutos profesionales no pudiesen impartir carreras que requiriesen licenciatura previa para su titulación, con el fin de evitar la enmarañada formación resultante de los decretos de años anteriores, su cambio de estatus.

Todo este escenario se desarrolla en el contexto del Dictamen $\mathrm{N}^{\circ} 43.184$, del 13 de junio de 2014, de la Contraloría General de la República, que conforme su texto plantea que los IP no pueden impartir las carreras que requieren de licenciatura previa que indica, desde la entrada en vigencia de la Ley N ${ }^{\circ} 20.370$, conocida como Ley General de Educación (LGE). Lo anterior encuentra refuerzo al señalar que los IP se tendrán que "abstener de ofrecer dentro de sus alternativas académicas carreras que requieran la licenciatura previa, en virtud de sus atribuciones fiscalizadoras sobre tales entidades" (Ministerio de Educación de Chile, 2014, p. 3).

Las carreras a las que se refiere esta ley corresponden a pedagogía, educación parvularia y periodismo. Es preponderante el anclaje de estos dictámenes con la LGE del 12 de septiembre de 2009, cuyo organismo regulatorio central, corresponde al Ministerio de Educacion (MINEDUC). De esta central jurídica, se destaca el artículo $\mathrm{N}^{\circ} 21$ :

La Educación Superior es aquella que tiene por objeto la preparación y formación del estudiante en un nivel avanzado en las ciencias, las artes, las humanidades y las tecnologías, y en el campo profesional y técnico. El ingreso de estudiantes a la educación superior tiene como requisito mínimo la licencia de educación media. La enseñanza de educación superior comprende diferentes niveles de programas formativos, a través de los cuales es posible obtener títulos de técnico de nivel superior, títulos profesionales, grados académicos o títulos universitarios o sus equivalentes (...) (Ministerio de Educación de Chile, 2009, p. 8).

El contenido precedente, en adición con el Dictamen $\mathrm{N}^{0}$ 43.184, resultan peculiares por cuanto durante los años 2014 y 2015 se tensiona la plataforma de dictación prescrita por la Ley 
$\mathrm{N}^{0}$ 20.054, pues hay instituciones de educación superior que dejan de impartir trabajo social o servicio social sin licenciatura: la esperanza parece devenir real. Siguiendo a Grau-Solés, Iñiguez-Rueda y Subirats (2010) se produce un movimiento particular que implica un nuevo enactment del trabajo social a escala de educación terciaria. Este dictamen evidencia un espacio en disputa pues se cuestiona la matriz materializada en la Ley $\mathrm{N}^{\circ} 20.054$ que, recordemos, supone el hito protagónico que conforma la triple fragmentación del trabajo social.

No obstante, solo un año después un nuevo Dictamen aparece en escena mediando en la conformación del trabajo social. Se trata del N 39.296 de fecha 15 de mayo de 2015, emanado por parte de la Contraloría General de la República de Chile, que en su texto general plantea que los IP que impartían las carreras de Trabajo Social o Asistente Social a la entrada en vigencia de la Ley $\mathrm{N}^{\circ}$ 20.054, pueden seguir haciéndolo, pero sin otorgar el pertinente grado de licenciado.

Con aquello, el estatus del trabajo social retoma la senda de los años noventa, cuando comenzaba la democracia en Chile y se ratificaba la triple fragmentación original de los ochenta ya comentada. Ahora el Dictamen N 39.296 de 2015 reafirma el orden y la vía de la trifurcación establecida por la Ley No 20.054 de 2005, coartando las expectativas que se habían desplegado en especial en 2014. Pero, además, se agrega una controversia explícita respecto de la duplicidad de estatus propiciada por el propio entramado de leyes, tal como se expresa en el siguiente extracto proveniente de la redacción del Dictamen $\mathrm{N}^{\circ} 39.296$ :

Asimismo, en el marco del Tercer Trámite Constitucional ante la Cámara de Diputados, la diputada señora Saa advierte sobre la dualidad de estatutos generados para la profesión en estudio, que involucra la de Trabajador Social, que únicamente podrán impartir las universidades, previo otorgamiento de la licenciatura, y la de Asistente Social, "que podrán seguir impartiendo los institutos profesionales que así lo deseen", "lo que, en sí mismo, es una protección para los institutos y sus alumnos (...) (Ministerio de Educación de Chile, 2015, p. 5).

\section{Coherencias paradójicas}

Este eje se encuentra en vínculo con el Nuevo Management Público (NMP), que transforma y conforma una nueva subjetivación en la administración pública y sus actores. El NMP intima al Estado tradicional para transformar sus estructuras fundamentales y ser proclive al mercado (Sisto, 2012), en particular en las prestaciones de alianzas públicas y privadas en Chile, que se construyen complejamente en una red de intercambios suscitados por prescripciones a los programas sociales, conforme una serie de dispositivos socio técnicos (Soto, Fardella, Valenzuela \& Carvajal, 2017).

En este tejido participa directamente el trabajo social, el cual requiere ser adaptado bajo lógicas neoliberales (Arriagada, 2017), contexto que encubre interpelaciones identitarias (Soto, Stecher \& Valenzuela, 2017) que resultan particulares. Por un lado, como disciplina, debe 
hacer frente a la estructuración que instrumentaliza la licenciatura en trabajo social; y por otro, desde la empleabilidad, asimilar su despliegue laboral en un espacio de competitividad que precariza (Sisto, 2009), performa su ideario, tradiciones (Castañeda \& Salamé, 2012) y en donde cabe preguntarse por un carácter reproductor más que transformador en su accionar, que emerge como utópico ante un proyecto de Estado mínimo (Echegaray, 2017).

Las características que se asumen en un Estado managerial desplazan progresivamente las responsabilidades de bienestar en las propias familias y colectividades, pues en la lógica (neo)liberal, cada uno es responsable de su propio desarrollo y adaptación a la oferta y demanda, en distintos circuitos cotidianos (Foucault, 2007).

Como se menciona precedentemente, este escenario resulta coherente con las problemáticas y déficits generales de las políticas neoliberales en otros sectores y países, que de seguro le resuenan al lector: las diferencias en el acceso a un empleo portando o no licenciatura, las bajas remuneraciones, los desafíos a la profesionalidad e identidad, entre otros. Resulta iconográfico representar el caso del trabajo social chileno ante la desprofesionalización implementada con la triple escala de titulación que termina por desvalorizar tanto formativa como laboralmente. Como vemos, la contradicción de la formación de instituto profesional y universitaria en el trabajo social se alinea coherentemente con las prescripciones del mercado laboral, que requiere de materialidades jurídicas sustentadas en la ideología del NMP.

Por ejemplo, a escala educativa con una formación basada en competencias, concepto referido a características personales que requieren ser conectadas con un contexto que direcciona qué se debe hacer efectiva y eficientemente (Fardella \& Sisto, 2015). Este tejido dialoga con una transformación profunda en las organizaciones, que deben propiciar plasticidad y permanente innovación para subsistir en un medio altamente competitivo. En consideración a lo anterior, se vale de contratos flexibles y temporales con prestación de servicios por proyectos o faenas específicas (Sisto, 2009), cuyos salarios y estabilidad laboral están sujetos al logro de resultados que se miden por indicadores, forjando un modelaje con orientación a la competencia individual y al emprendimiento (Sisto, 2012).

Para el caso del trabajo social lo importante es propiciar la competencia, emergiendo órdenes y normas que lo propician, inclusive se imbuyen en su significado, terminando por abultar e incluso confundir su denominación: “3.- Agrégase la siguiente letra q), nueva: “q) Título de Trabajador Social o Asistente Social: Licenciado en Trabajo Social o en Servicio Social, respectivamente". (Ministerio de Educación de Chile, 2015, p. 1). Por ende, se homologa al trabajador social con el asistente social.

Todo aquello se refuerza con el Dictamen No 39.296, del 15 de mayo de 2015, que ratifica la formación de instituto profesional y universitaria como se expresa en otros artículos de la Ley No20.054:

Artículo $2^{\circ}$. - Los Institutos Profesionales que imparten las carreras de Trabajador Social o de Asistente Social, podrán continuar otorgando el título profesional correspondiente. 
Artículo $3^{\circ}$.- Las Universidades que impartan la carrera de Trabajo Social deberán establecer planes y programas especiales para los Asistentes Sociales que hubieren obtenido su título profesional en Institutos Profesionales reconocidos por el Estado, con la finalidad que puedan cursar en ellas y optar al grado de licenciado en Trabajo Social y al título profesional de Trabajador Social (...) (Ministerio de Educación de Chile, 2015, p. 1).

Por tanto, estas normativas median dictaminando una vigilancia por parte de las profesiones sobre todo cuando aparecen objetivos de producción cuantitativa y cualitativa desde una lógica del NMP. La nomenclatura que da cuenta en Chile de varios trabajos sociales, la existencia de un aparato público disminuido y la oferta de programas sociales en el mercado de prestaciones, gradualmente configuran un accionar profesional heterogéneo, paradójico, cercano al emprendimiento y coherente con las visiones gerencialistas del NMP, en donde la acreditación y certificación de competencias sobre determinadas áreas resulta primordial.

Cabe en aquel contexto cuestionarse por la coherencia o resistencia a la paradoja del capital por parte de profesionales, aprendices y maestros del trabajo social. Sin dudas una asignatura pendiente en nuestros días.

\section{CONCLUSIONES}

El desarrollo del artículo da cuenta cómo el trabajo social chileno en las últimas tres décadas ha sido mediado y constituido por materialidades en sus saberes y prácticas, emergiendo un ordenamiento sobre bases jurídicas andamiadas en una era neoliberal (Vivero, 2016), que configura para la profesión, su propia problematización en la post dictadura (Molina, 2016).

La fuerza de las políticas neoliberales se observa indeleble, sin embargo, la ANT bosqueja alternativas de cambio a través de la descajanegrización, ese ejercicio de volver visible y problematizable aquello dado por hecho, pues lo social es un movimiento de asociación permanente. Por tanto, al volverse visible, cuestionado puede ser repensado, y si nos centramos en el trabajo social, neo reconceptualizado (Vivero, 2016).

De acuerdo a lo detallado, la cajanegrización del trabajo social parece compacta, no obstante, desde la ANT es posible comprender ese proceso de ocultamiento como la duración de una posición que no necesariamente debe explicarse por su poder, sino también por la convergencia y vínculos que la despliegan (Grau-Solés et al. 2010), en el caso concreto aquí explicado, las relaciones mediadoras de las distintas leyes y decretos en el enactment del trabajo social chileno contemporáneo.

Pero no solo eso, puesto que las relaciones de actantes humanos y no-humanos pueden fracasar, ya que la dominación no es estática, ésta debe ser desplegada, reparada y mantenida. Incluso los efectos de determinada traducción no son imperecederos, pues volverán a ser traducidos desde el momento en que se produzca una alteración. 
En consecuencia, como señala Molina (2016), es importante comprender los trazos configurados en un devenir histórico, en este caso, entre cada una de las materialidades, particularmente las acaecidas entre los dictámenes que constituyen blancos para comprender las convergencias, pero también reemsambles en otra red de conexiones, para un nuevo enact del trabajo social, actualmente interpelado en su nivel disciplinario y pragmático (Viveros, 2016).

Entonces resulta interesante hacer emerger el tejido entre estos dictámenes, pues tensiona los efectos concebidos en fases anteriores (Latour, 2005). Seguidamente, conectarse y asociarse a nuevas redes se convierte en una responsabilidad para los trabajadores sociales con y sin licenciatura, aprendices, gremio y maestros, pues cada partícipe se constituye en sí mismo en modificador y creador de efectos, pues para Latour no hay informaciones, hay transformaciones, y aquello es menester propiciar en un nuevo enact del trabajo social chileno.

Cabe destacar que, si en la actualidad, el trabajo social se enacta por una trifurcación, la liquidación de una esperanza y una coherencia paradójica, son necesarios otros caminos de asociación y resistencia ante las variadas amenazas que se determinan sobre su práctica y que obedecen a criterios fundados por el NMP, que la relegan a un plano tecno burocrático y pragmático (Vivero, 2016). Pero también por la precariedad laboral, forjada escalonadamente desde comienzos de los ochenta con procesos graduales de disminución del Estado y un aumento de la flexibilidad laboral, acarreando incertidumbres y ausencias de garantías en las condiciones de trabajo en diversos escenarios laborales en que se desenvuelven no solo los trabajadores sociales, sino que también otras profesiones de las ciencias humanas.

Por ello, un nuevo enactment del trabajo social debe dibujar una nueva traducción sobre la recuperación del rango universitario para conectar innovadoras formas de acción colectiva, fortaleciendo el compromiso ético político de trabajadores sociales producidos y prescritos, tanto universitaria como institutanamente. En síntesis, comprender nuestra posición privilegiada para repensar los cambios socio estructurales demandados por diversos movimientos sociales (Molina, 2016) que tensionan las materialidades de corte neoliberal que enactan, tanto a la esfera societal, como actualmente al trabajo social.

\section{REFERENCIAS}

Arriagada, L. V. (2017). Desafíos de una práctica ético-política. El trabajo social chileno postdictadura. Revista Katálysis, 20(3), 344-352.

Aspeé, J. (2016). Análisis Longitudinal de la exclusividad universitaria del trabajo social. Rumbos, 13(1), 10-32.

Biblioteca del Congreso Nacional de Chile. (1990). Ley N $\mathrm{N}^{\circ}$ 18.962. Recuperado de: https:// www.leychile.cl/Navegar?idNorma=30330. Acceso en: 5 sep. 2018. 
Brezmes, M. (2009). El Trabajo Social en el espejo: el reflejo de una legislación. Zerbitsuan, $46,121-132$.

Bruni, A. (2005). Shadowing software and clinical records: On the ethnography of non-humans and heterogeneous contexts. Organization, 12(3), 357-378.

Castañeda, P., \& Salamé, A. (2012). Profesionalidad del Trabajo Social chileno: tradición y transformación. Temuco: Ediciones Universidad de La Frontera.

Castillo, V., \& Rodríguez, G., C. (2016). Los problemas del stock en campos profesionales difusos: Oferta educativa en Trabajo Social. Estudios pedagógicos, 42(1), 37-52.

Echegaray, A. H. (2017). La precarización laboral como factor de la desprofesionalización del Trabajo Social. Análisis y propuestas desde la perspectiva experta. Documentos de Trabajo Social, 59, 117-139.

Fardella, C., \& Sisto, V. (2015). Nuevas Regulaciones del trabajo docente en Chile. Discurso, subjetividad y resistencia. Psicología y Sociedades, 27(1), 68-79.

Foucault, M. (2007). El Nacimiento de la Biopolítica. Buenos Aires: Fondo de Cultura Económica. Flick, U. F. (2012). Introducción a la investigación cualitativa. Madrid: Ediciones Morata.

Gálvez, A. M. (2005). Sociabilidad en pantalla. Un estudio de la interacción en los entornos virtuales. AIBR, Revista de Antropología Iberoamericana, noviembre-diciembre, 1-29.

Geertz, C. (2003). La interpretación de las culturas. Barcelona: Gedisa.

Grau-Solés, M., Iñiguez Rueda, L., \& Subirats, J. (2010). La perspectiva sociotécnica en el análisis de políticas públicas. Psicología Política, 41, 61-80.

González, M. (2010). Historias del Trabajo Social en Chile 1925-2008. Santiago de Chile: Ediciones Técnicas de Educación Superior.

Guba, E., \& Lincoln, Y. (1994). Handbook of qualitative research. Thousand Oaks, CA: Sage.

Iturrieta, S. (2012). Desafíos del trabajo social en un campo laboral con límites profesionales difusos. Katalysis, 15(2), 163-172.

Latour, B. (1994). On Technical Mediation. Philosophy, Sociology, Genealogy. Common Knowledge, 3(2), 29-64.

Latour, B. (2001). La Esperanza de Pandora: Ensayos sobre la realidad de los estudios de la ciencia. Barcelona: Gedisa.

Latour, B. (2005). Reensamblar lo social: una introducción a la teoría de actor red. Buenos Aires: Manantial.

Matus, T. (2016). Los desafíos de refundar: paradojas de redistribución y reconocimiento del trabajo social. En P. Vidal Molina (Ed.), Trabajo Social en Chile. Un siglo de trayectoria. (pp. 293-349). Santiago de Chile: RIL Editores.

Michael, M. (2017). Actor-Network Theory: Trials, Trails and Translations. London: Sage.

Ministerio de Educación Pública de Chile. (1981a). Decreto con Fuerza de Ley N¹. Recuperado de: https://www.leychile.cl/Navegar?idNorma=3394. Acceso en: 5 sep. 2018.

Ministerio de Educación Pública de Chile. (1981b). Decreto con Fuerza de Ley N5. Recuperado de: https://www.leychile.cl/Navegar?idNorma=3668. Acceso en: 5 sep. 2018. 
Ministerio de Educación de Chile. (2005). Ley N²0.054. Recuperado de: https://www.leychile. cl/Navegar?idNorma=242374. Acceso en: 5 sep. 2018.

Ministerio de Educación de Chile (2009). Ley N 20.370. Recuperado de: https://www.leychile. cl/Navegar?idNorma=1006043. Acceso en: 5 sep. 2018.

Ministerio de Educación de Chile. (2014). Dictamen $\mathrm{N}^{\circ}$ 43.184. Recuperado de: http://www. contraloria.cl/appinf/LegisJuri\%5Cboletinjurisprudencia.nsf/DetalleDictamenBoletin ?OpenFormyUNID=4A5F697B8E22C09384257CFA007DCAF8. Acceso en: 5 sep. 2018.

Ministerio de Educación de Chile (2015). Dictamen $\mathrm{N}^{\circ}$ 39.296. Recuperado de: http:// www.contraloria.cl/mesaprueba/842577F8004BAD41/0/F7C2630FA4D02F31032 57E4A00774CEF. Acceso en: 5 sep. 2018.

Molina, W. (2016). Cuestión social, transformaciones socio estructurales y trabajo social en Chile post dictadura. En P. Vidal Molina (Ed.), Trabajo Social en Chile. Un siglo de trayectoria. (pp. 197-221). Santiago de Chile: RIL Editores.

Sisto, V. (2009). Cambios en el trabajo, identidad e inclusión social en Chile: desafíos para la investigación. Universum, 24(2), 192-216.

Sisto, V. (2012). Análisis del Discurso y Ppsicología: a veinte años de la Revolución Discursiva. Revista de Psicología, 21(1), 185-208.

Sisto, V., \& Fardella, C. (2014). El eclipse del profesionalismo en la era de la Rendición de Cuentas-Modelando Docentes en el Contexto del Nuevo Management Público. Cadernos de Educação, 49, 03-23.

Soto, Á., Fardella, C., Valenzuela, A., \& Carvajal, F. (2017). Las funciones performativas de los instrumentos en las redes de acción pública. Psicoperspectivas, 16(3), 76-86.

Soto, Á., Stecher, A., \& Valenzuela, A. (2017). Identitary interpellation in the workplace: Proposal for understanding the processes of identity construction at work. Estudos de Psicologia (Campinas), 34(1), 25-39.

Stengers, I. (2005). The cosmopolitical proposal. En B. Latour \& P. Wibel (Eds.), Making Things Public (pp. 994-1003). Cambridge: MIT Press.

Rodríguez, M., \& Vidal, P. (2013). Transformación (es) del trabajo en tiempo (s) de precariedad y resistencia(s). Algunas Aproximaciones desde Latinoamérica. Perspectivas, 24, 217218

Vidal P. (2016). Trabajo social en Chile: Un siglo de trayectoria. Santiago de Chile: RIL Editores Vivero, L. (2016). El Trabajo Social En La Era Neoliberal: Desafíos Para Una Neo Reconceptualización. En P. Vidal Molina (Ed.), Trabajo Social en Chile. Un siglo de trayectoria (pp. 175-196). Santiago de Chile: RIL Editores.

Woolgar, S., \& Lezaun, J. (2015). Missing the (question) mark? What is a Turn to Ontology? Social Studies of Science, 45(3), 462-467.

Yin, R. K. (1994). Case Study Research. Design and Methods. London: SAGE. 